$\frac{180}{9-24-86}$ ST (2) 40 cyp to would

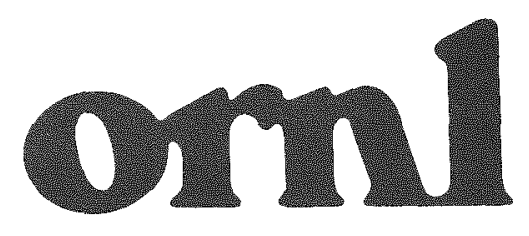

OAKRIDGE

NATIONAL

LABORATORY

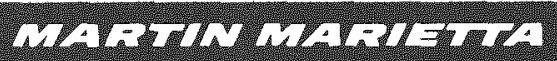

\section{Ultrasonic Detection of Laminar-Type Defects in Iridium Alloy Blanks}

OPERATED BY

MARTIN MARIETTA ENERGY SYSTEMS, INC

FOR THE UNITED STATES

DEPARTMENT OF ENERGY
K. V. Cook

R. A. Cunningham, Jr.

W. A. Simpson, Jr.

R. W. McClung

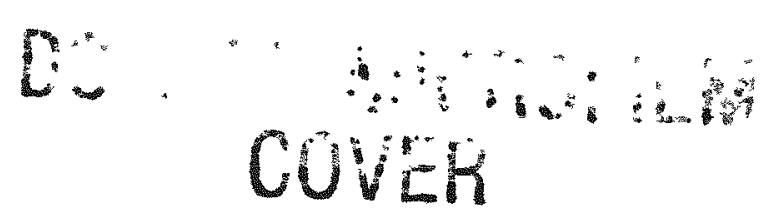




\section{DISCLAIMER}

This report was prepared as an account of work sponsored by an agency of the United States Government. Neither the United States Government nor any agency Thereof, nor any of their employees, makes any warranty, express or implied, or assumes any legal liability or responsibility for the accuracy, completeness, or usefulness of any information, apparatus, product, or process disclosed, or represents that its use would not infringe privately owned rights. Reference herein to any specific commercial product, process, or service by trade name, trademark, manufacturer, or otherwise does not necessarily constitute or imply its endorsement, recommendation, or favoring by the United States Government or any agency thereof. The views and opinions of authors expressed herein do not necessarily state or reflect those of the United States Government or any agency thereof. 


\section{DISCLAIMER}

Portions of this document may be illegible in electronic image products. Images are produced from the best available original document. 


\section{Printed in the United States of America Avallable from National Technical Information Service \\ US Department of Commerce \\ 5285 Port Royal Road, Springfield, Virginia 22161 NTIS price codes-Printed Copy A03 Microfiche A01}

This report was prepared as an account of work sponsored by an agency of the United States Government Nether the Untted States Government nor any agency thereof nor any of their employees makes any warranty express or implied, or assumes any legal liability or responsibility for the accuracy completeness, or usefulness of any information, apparatus product, or process disclosed or represents that Its use would not infringe privately owned rights Reference heren to any specific commercial product, process or service by trade name trademark manufacturer, or otherwise, does not necessanly constitute or imply its endorsement, recommendation, or favoring by the United States Government or any agency thereof The views and op mions of authors expressed herein do not necessarily state or reflect those of the United States Government or any agency thereof 
METALS AND CERAMICS DIVISION

ORNL --6290

DE86 015976

ULTRASONIC DETECTION OF LAMINAR-TYPE DEFECTS

IN IRIDIUM ALLOY BLANKS

K. V. Cook, R. A. Cunningham, Jr., W. A. Simpson, Jr., and $\mathrm{R}$. W. McClung

Date Published: July 1986

Prepared for

DOE Division of Special Applications

Prepared by the

OAK RIDGE NATIONAL LABORATORY

Oak Ridge, Tennessee 37831

operated by

MARTIN MARIETTA ENERGY SYSTEMS, INC.

for the

U.S. DEPARTMENT OF ENERGY

under Contract No. DE-AC05-840R21400 
page blank

ii 
CONTENTS

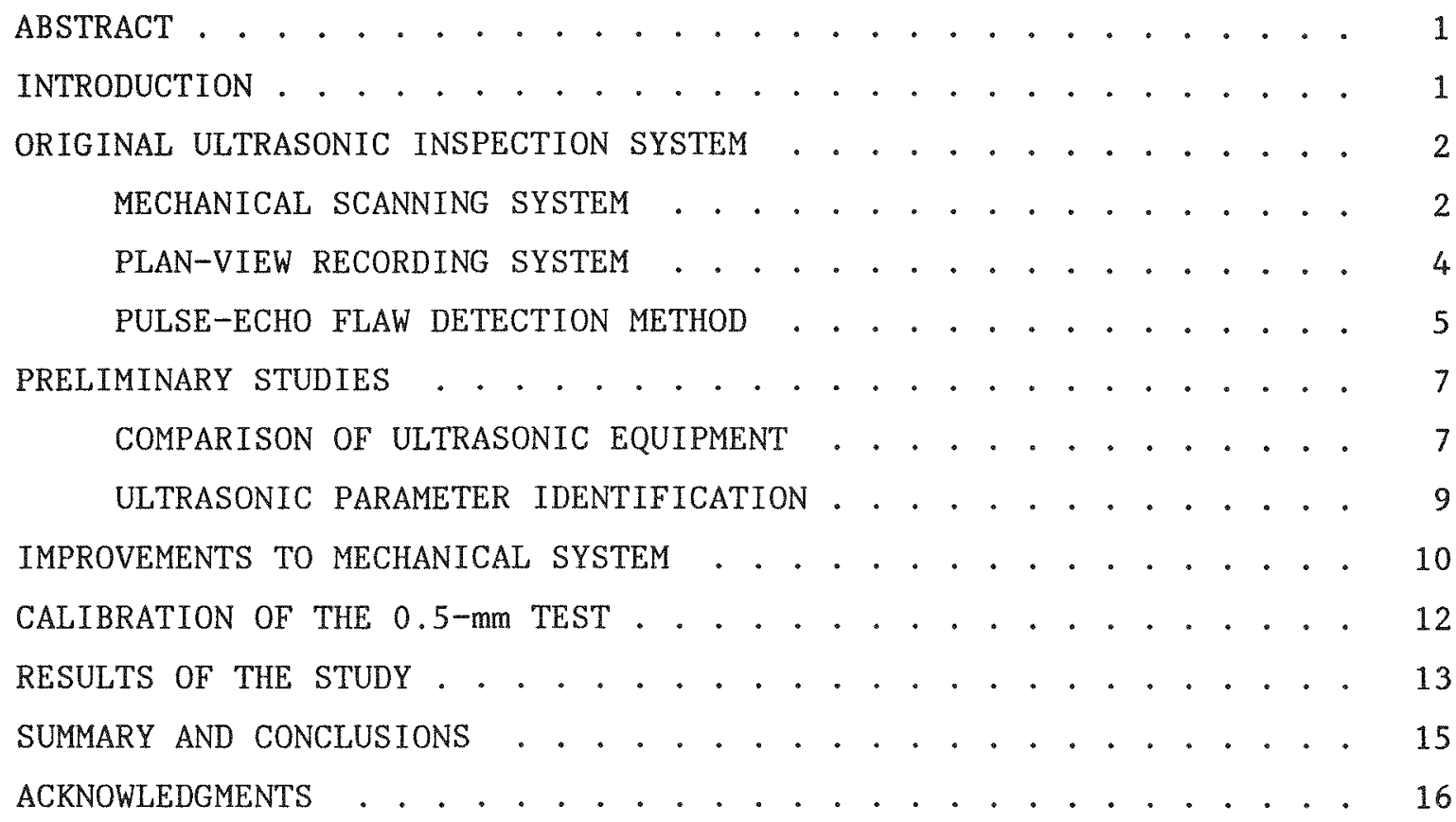


K. V. Cook, R. A. Cunningham, Jr., W. A. Simpson, Jr., and $\mathrm{R}$. W. McClung

\title{
ABSTRACT
}

\begin{abstract}
Encapsulated isotopic heat sources for use in generating electrical power for space applications require flight-quality hardware material. Iridium is the chosen material for such applications, and Oak Ridge National Laboratory has been the prime supplier of iridium alloy forming blanks $52 \mathrm{~mm}$ in diameter by $0.66 \mathrm{~mm}$ thick ( 2.0 by $0.026 \mathrm{in.})$. Prior to the work reported here, these blanks were ultrasonically examined by using 0.9-mm-diam (0.035-in.) simulated flaw standards. However, as a result of this effort, the sensitivity of our ultrasonic pulseecho test system has been increased. The improved ultrasonic test system permits blank inspection at the 0.5 -mm-diam (0.020-in.) simulated flaw detection level. This test system was successfully demonstrated on the initial blanks provided via an improved processing route (consumable arc-melting, extruding, and rolling). The equipment modification and/or selection and the specific focused search unit immersion technique developed to provide this capability are described. The improved flaw detection capability also provides data maps of a common type of defect in iridium (delaminations).
\end{abstract}

\section{INTRODUCTION}

For several years, the Oak Ridge National Laboratory (ORNL) has supplied Monsanto Research Corporation, Mound Plant, with flight-quality iridium hardware components through a U.S. Department of Energy (DOE) contract. A primary objective has been to provide iridium encapsulation materials for the isotopic heat source used to produce electrical power for space applications. One of the recent efforts required improvement by the Nondestructive Testing Group (Metals and Ceramics Division of ORNL)

*Research sponsored by the Division of Special Applications, Office of Defense Energy Projects and Special Applications, Office of Nuclear Energy, U.S. Department of Energy. 
of the ultrasonic detection system that has been used to inspect for laminar-type defects in iridium blanks. These blanks, which are formed into cups by the Mound Plant for encapsulation of the isotope, are circular disks with a diameter of $52.1 \mathrm{~mm}(2.05 \mathrm{in.})$ and a thickness of $0.63 \mathrm{~mm}$ ( $0.025 \mathrm{in.})$. The quality assurance program for flight-quality hardware in place at ORNL has required the detection of $0.9-\mathrm{mm}(0.035-\mathrm{in}$. simulated flaws; however, the new goal was to establish a test system to detect a 0.5 -mm-diam (0.020-in.) simulated flaw. We have established an ultrasonic test system that will detect 0.5 -mm-diam simulated flaws in the blanks. This report documents the techniques used to detect simulated flaws according to current requirements and also describes our improved sensitivity activities.

Intermediate events to achieve the improved sensitivity included (1) the identification of equipment and search units, (2) the design and/or assembly of a laboratory inspection system, (3) the establishment of procedures, and (4) the demonstration of system performance on improved flight-quality hardware blanks.

ORIGINAL ULTRASONIC INSPECTION SYSTEM

MECHANICAL SCANNING SYSTEM

The inspection technique that has been performed on blanks by ultrasonics used a long immersion (water couplant) tank facility originally assembled for nuclear reactor fuel plate inspection. Figure 1 shows the original fuel plate inspection setup. A section of the immersion tank is shown at the bottom left side of the photograph. The mechanical system used to raise and lower the ultrasonic transducer assemblies (the two long vertical search tubes) is mounted on top of the immersion tank. The stepping motor used to perform this operation is located between the two search tubes. The long table mounted over the immersion tank to the right of the ultrasonic system is the plan-view C-scan recording device that provides one-to-one recording of flaw data. The controller mechanism blocks the view of part of the recording table (right side of photograph). This facility has been modified for blank inspection by simulating a rectangular fuel plate with a frame in which eventually 12 blanks [52.1 $\mathrm{mm}(2.05 \mathrm{in.})$ in diameter] and two standards 


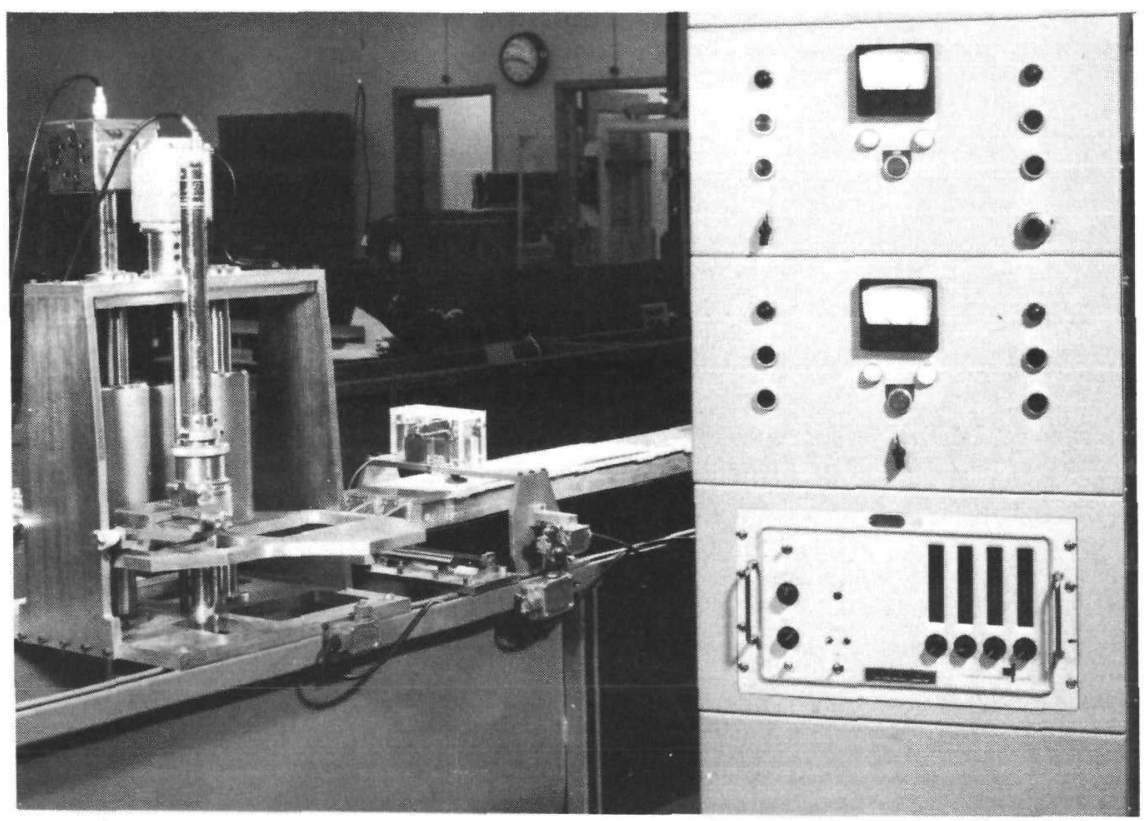

Fig. 1. Ultrasonic system originally used to inspect nuclear-grade fuel plates for delaminations.

were sandwiched. The blanks are loaded into round circular cutouts or windows in a thick brass plate and held in place by a thinner overlapping brass plate (again with circular cutouts or windows) so that approximately $0.8 \mathrm{~mm}$ ( $0.032 \mathrm{in.})$ of the outer diameter of the blanks is clamped between plates (via machined edges), and access to the major area of the blanks for the interrogating ultrasonic beam is via the circular holes or windows in the frame holder. Figure 2 shows the original 13-blank holder (frame) used for larger diameter blanks. One blank is shown on the edge of the holder. This frame is aligned on a dovetail slide that is supported and driven by two roller chains riding in guides welded to two long alignment rods. Alignment is further maintained by cam-activated pinch wheel rollers. These wheels carry the frame assembly, via the rods, along the water-filled immersion tank. 


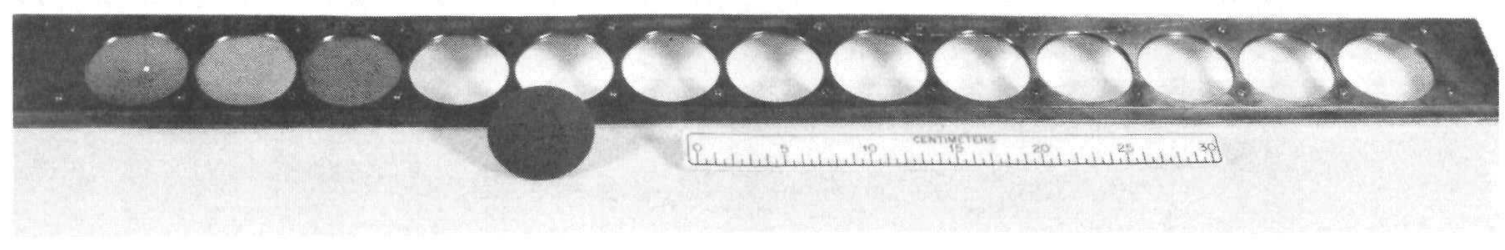

Fig. 2. Original frame holder used to align blanks for ultrasonic inspection to detect delaminations with a pulse-echo technique. One blank is shown on the edge of the holder.

Scanning of the frame assembly is accomplished by horizontally moving (via a large dc motor, a clutch mechanism, and a geared chain-drive mechanism) the blank holder past a stationary ultrasonic search unit assembly (first one direction and then the other). The search unit is raised vertically by $0.5 \mathrm{~mm}$ ( $0.020 \mathrm{in}$.) at each end of the scan, thereby providing $x$ (longitudinal) and $y$ (vertical scan) data for the generation of plan-view or C-scan recordings.

\section{PLAN-VIEW RECORDING SYSTEM}

The $x-y$ recordings are produced with an electrically activated pen (electrical dc current supplied by the ultrasonic flaw detector amplifier if a flaw is detected). This pen is mechanically driven along a currentsensitive paper in synchronization with the scan and index. The same chain-drive system that moves the blank holder also moves the pen longitudinally (the plastic box shown above the recording table in Fig. 1 supports the pen mechanism) while the recorder table is indexed (at each end of the longitudinal scan motion) with a stepping motor that is paralleled with an identical motor raising (or lowering) the search unit assembly. Thus, C-scan records are generated on dry current-sensitive recorder paper that shows flaws as black on white. Further, the edges of the overlap plate on the blank holder are beveled, which generates an ultrasonic response that locates the approximate outer diameter of the blanks. 
PULSE-ECHO FLAW DETECTION METHOD

A pulse-echo flaw detection method that uses a piezoelectric transducer to generate and detect high-frequency ultrasonic energy is used to detect delaminations in the 0.63-mm-thick (0.025-in.) blanks. Water is used to couple the ultrasonic pulsed signals from the transducer to the blank and vice versa. Thus the term pulse echo for this type inspection.

The ultrasonic energy generated by the transducer is focused near the part entry surface to produce maximum energy on a small area of the blank. Figure 3 illustrates the focused sound beam employed in the pulse-echo method. The 15-MHz transducer used originally did not resolve the first back-surface echo from the thin blanks. However, multiple signals from the back surface are resolved. These multiple back-surface signals are produced by sound reflecting back and forth between the entry and back surfaces of the blanks. The delay in signal arrival time, produced by the longer paths of the multiple reflections, provides enough time for the overloaded receiver amplifier to recover so that the relatively small back-surface reflections can be resolved. In particular, the third back-surface signal is easily resolved; therefore, this is the primary signal monitored for amplitude changes to detect delamination. Figure 4 illustrates the A-scan video display as seen on a flaw detection cathoderay tube for the pulse-echo method just described.

When a delamination is present, all back-surface signals are reduced in amplitude (dependent on the size and orientation of the delamination). This signal height reduction is primarily due to scattering of the higher frequency components from the flaws, but it may also be reduced because of the longer dead time (overloaded) response of the amplifier that is produced by the earlier arriving flaw-reflected signals. In any event, by monitoring both the third and fourth multiple of the back surface at the same time, an additional benefit occurred. This benefit was the outlining of the outer diameter of the blank by scattering of $f$ the beveled edges of the holder. Thus, we monitored both signals with an electronic 
ORNL-DWG 85-18329

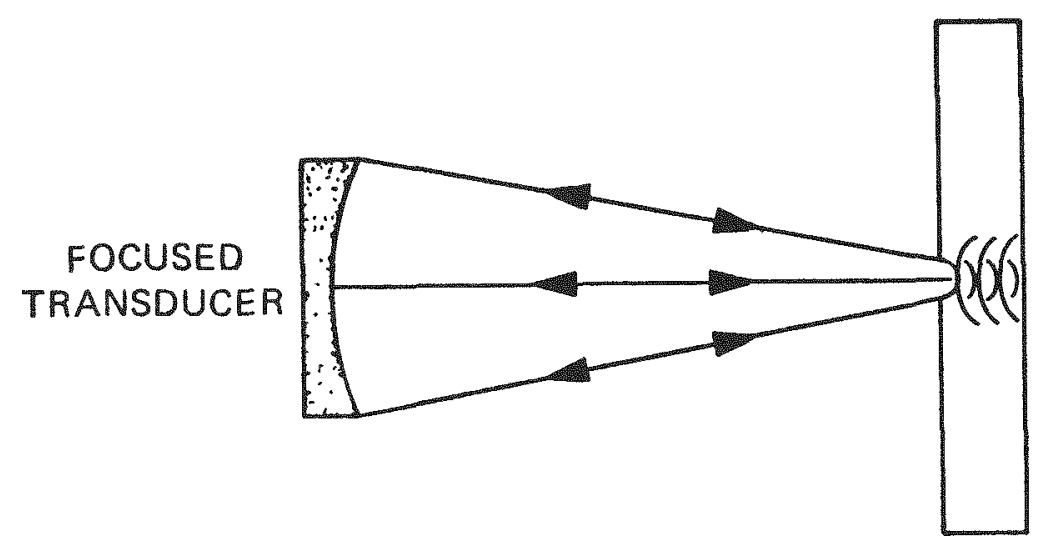

Fig. 3. Focused sound beam employed in the pulse-echo method of inspecting for delaminations in blanks.

ORNL-DWG 85-18328
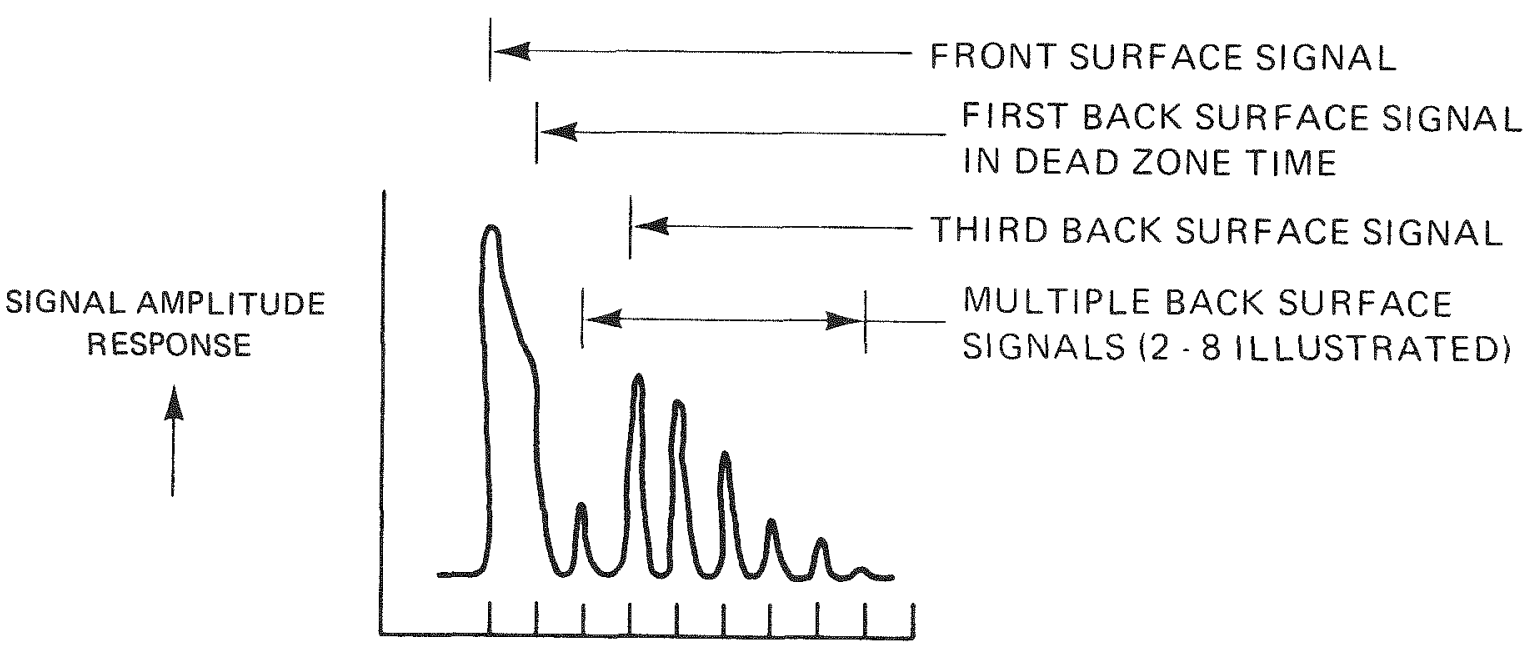

SIGNAL ARRIVAL TIME

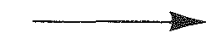

Fig. 4. Video display (A-scan) as seen on a flaw detector cathode ray tube for the pulse-echo ultrasonic inspection of blanks. 
gate and used them to produce C-scan records of the flaw detection inspection. Figure 5 shows simulated* data for (1) a calibration blank, (2) a good blank, and (3) a delaminated (flawed) blank.

The ultrasonic method employed for the laminar flaw test used an older vacuum tube flaw detector, a nominal $15-\mathrm{MHz}$ focused search unit, and a pulse-echo, water-coupled ultrasonic flaw detection method. Three of the older model flaw detection units (supposedly identical units) were available for this inspection; however, only one had sufficient response to detect the reference flat-bottom holes machined in a rejected iridium blank (located in an acceptable area on the rejected blank). We did not measure the actual frequency response of the system (although it was near $15 \mathrm{MHz}$ ); however, the test was reliable, reproducible, and successfully applied for years on a go-no-go basis. Only when an improved sensitivity was required did the actual parameters need to be better defined. of course, it would have been difficult to select proper backup search units and equipment with the go-no-go type system when and if failure occurred. Thus, we felt that, as an added benefit, the effort for improved sensitivity should provide the capability to select replacement and/or backup components.

\section{PRELIMINARY STUDIES}

\section{COMPARISON OF ULTRASONIC EQUIPMENT}

The frame holder containing blanks with simulated flaws of $0.5 \mathrm{~mm}$ was placed horizontally in our small research immersion tank $f$ so that $x-y$ scans and one-to-one C-scan recordings could be made. The small tank was used primarily because scans across one or two blanks could be made easily (i.e., the scans were accomplished quicker and more conveniently for limited scanning). Three commercial flaw detection units (i.e., two

* Simulated plan-view data are used to provide maximum quality illustrations; however, very good quality C-scan data are obtained by the test and are copied directly for use in less formal reports.

fAutomation Industries, Inc., Sperry Division, Shelter Rock Road, Danbury, CT 06810 . 


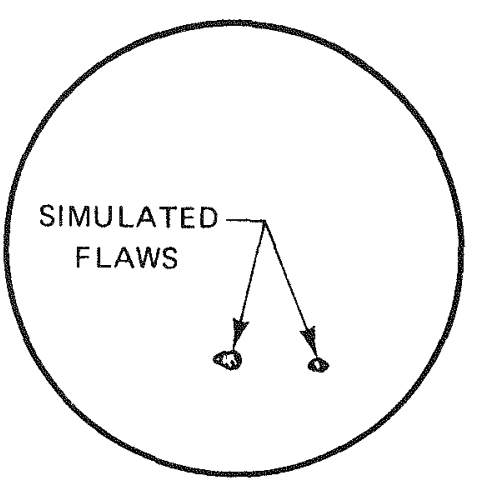

CALIBRATION BLANK WITH TWO SIMULATED FLAWS (i.e. FLAT BOTTOM HOLES OF 1.73 AND $0.89 \mathrm{~mm}$ DIAMETERS)

ORNL-DWG 85-18326

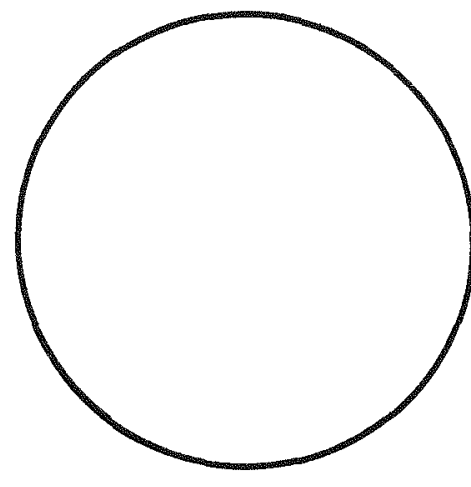

GOOD BLANK

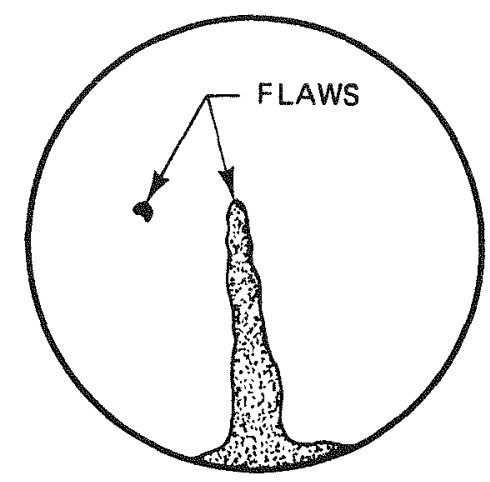

FLAWED BLANK

Fig. 5. Simulated plan-view flaw detection data for a calibration blank that contains $1.73-$ and $0.89-\mathrm{mm}$ simulated flaws, a good blank, and a delaminated blank, respectively.

stand-alone systems, a USIP-12\% and S-80 Reflectoscope ${ }^{\dagger}$ ) and a modular system (Panametrics were evaluated to see if $0.5-\mathrm{mm}$ flaw detection was feasible. The USIP-12 flaw detector was provided by Detek*t on a loan basis, and the other two were in-house systems purchased from Automation and Panametrics for other programs. Both stand-alone flaw detection units (USIP-12 and S-80) are nominal 25-MHz frequency response units, whereas the modular system works up to $35 \mathrm{MHz}$. Al1 were found to be adequate for the $0.5-\mathrm{mm}$ flaw detection if the proper search unit was selected. We chose to use the $\mathrm{S}-80$ because multiple units could be available simply by purchasing additional plug-in modules. Figure 6 shows the top of the small immersion tank with the Automation S-80 unit on top of the control bridge unit.

*Krautkramer-Branson, Inc., 250 Long Beach Boulevard, Stratford, CT 06497.

†utomation Industries, Inc., Sperry Division, She1ter Rock Road, Danbury, CT 06810 .

Panametrics, 221 Crescent St., Waltham, MA 02154.

*'Detek, Inc., 6805 Coolridge Dr., Temple Hills, MD 20748. 


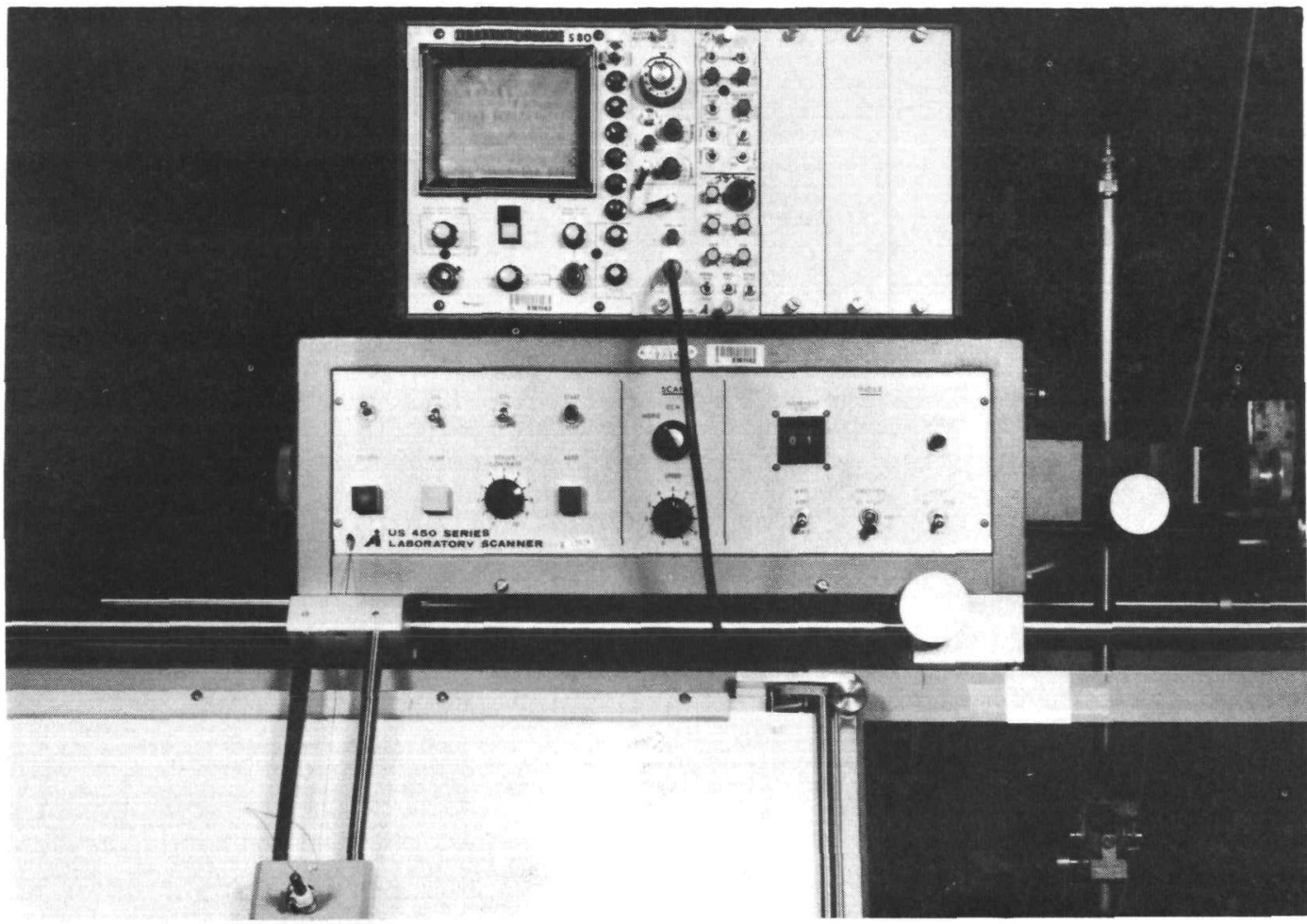

Fig. 6. Research immersion tank system with $\mathrm{S}-80$ and Automation Industries flaw detector atop the bridge control unit.

\section{ULTRASONIC PARAMETER IDENTIFICATION}

We used a Tektronix 7704A oscilloscope* with a spectrum analyzer (Tektronix mode1 7L12) to do spectrum analysis on the flaw and/or surface-reflected signals. Our real-time frequency monitoring of these radio-frequency ( $\mathrm{rf}$ ) signals is dependent on proper impedance matching between the ultrasonic instrument and the spectrum analyzer. Thus, we had to modify the receiver sections of our commercial S-80 Reflectoscope. This modification required the addition of a buffer module to our PR-3S plug-in unit (a solid-state pulser-receiver unit with a bandwidth of $25 \mathrm{MHz})$. No attempt was made to interface the analyzer with the older vacuum tube flaw detectors, since we knew that their sensitivities would not be adequate and that interfacing would require more effort than for the solid state flaw detectors.

*Tektronix, Inc., P.0. Box 1700, Beaverton, OR 97075. 
The subsequent investigation of the actual inspection frequency of various search units and the observed response from simulated flaws allowed us to select a particular search unit design for the $0.5-\mathrm{mm}$ (0.020-in.) detection required. The search unit selected for operation with the S-80 system, including the PR-3S pulser-receiver, is a spherically focused $6.3-\mathrm{mm}(0.25-\mathrm{in}$ ) element, with a nominal 20-MHz frequency response. The unit is focused at approximately $51 \mathrm{~mm}(2.0 \mathrm{in.})$ in water and has a peak frequency response of about 18 to $20 \mathrm{MHz}$. Figure 7 shows the spectrum analysis data for the unit selected. Ancillary equipment other than the oscilloscope and spectrum analyzer required to obtain the real-time frequency response includes a commercial stepless gate module (Panametrics 5052G) and a trigger interface module designed and fabricated by ORNL. Figure 8 shows the primary spectrum analysis system (the ancillary units are not shown) used for real-time readout monitoring of the test frequency.

\section{IMPROVEMENTS TO MECHANICAL SYSTEM}

We felt that the second-generation specimen holder used for the detection of $0.9-\mathrm{mm}$ simulated flaws was not adequate for the improved sensitivity requirement to detect $0.5-\mathrm{mm}$ flaws. Thus, we had a sturdier and straighter holder made for the $0.5-\mathrm{mm}$ sensitivity test with a space of appropriate diameter provided for a ground-surface standard instead of the rolled-surface one used with the 0.9-mm system. We also observed the declining stability of our mechanical scanning system; therefore, we knew that refurbishment and/or redesign of the scanning facility would be required for the more sensitive test.

Our mechanical scanning system was modified to establish the mechanical stability required for improved inspection sensitivity. We worked with field engineering personnel from the Plant and Equipment Division at ORNL to redesign the guide roller assemblies used to scan along two guide rails. These $\mathrm{V}$-shaped guide roller assemblies were replaced with spring-loaded special design assemblies using roller bearings. After repositioning one of the new roller bearing assemblies to eliminate instability produced by the rail-joint connections, we 
ORNL-DWG 86-1893

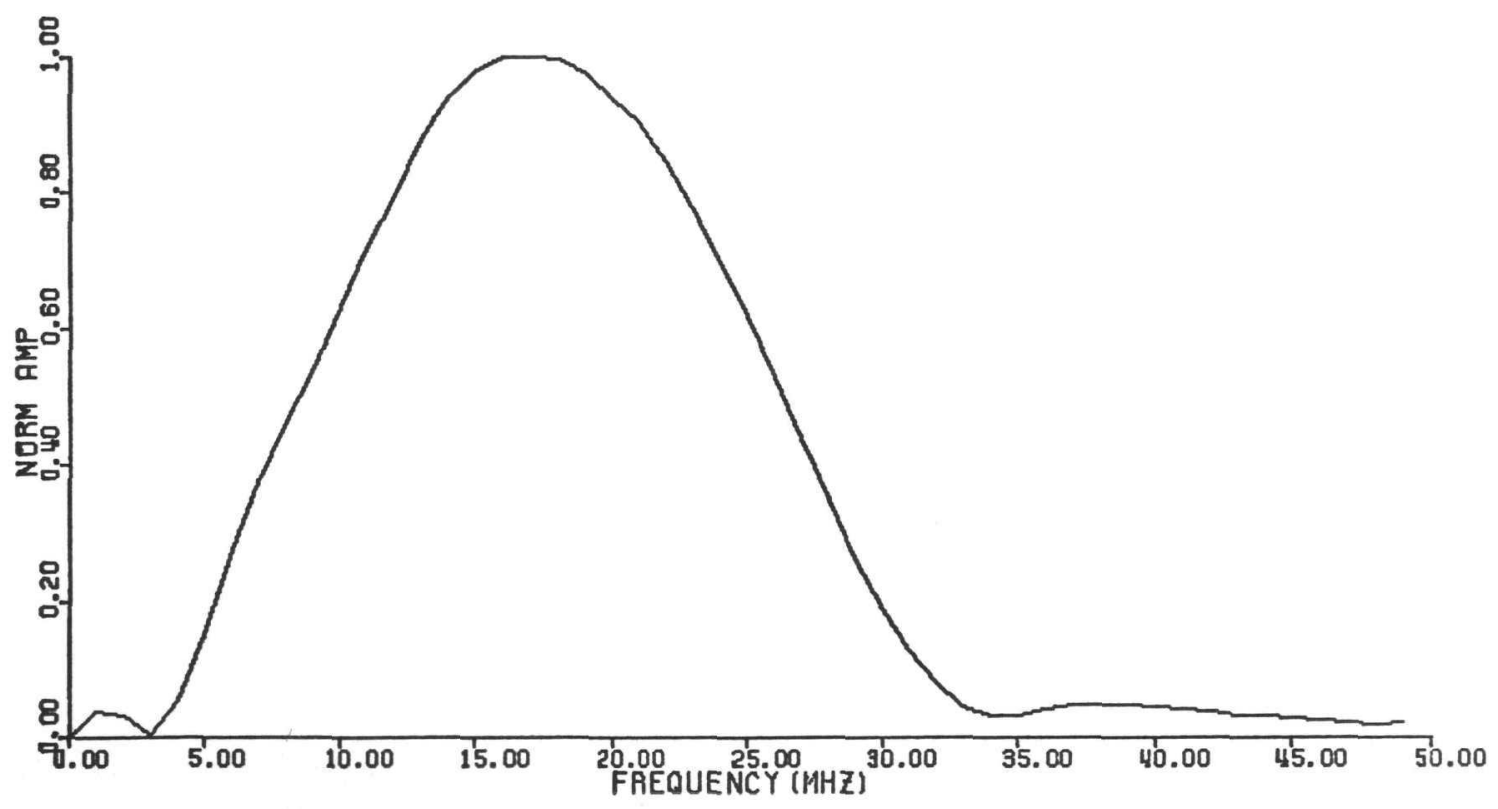

Fig. 7. Normalized spectrum analysis data for a spherical focused search unit with a nominal $20-\mathrm{MHz}$ frequency response.

ORNL-PHOTO 6104-84

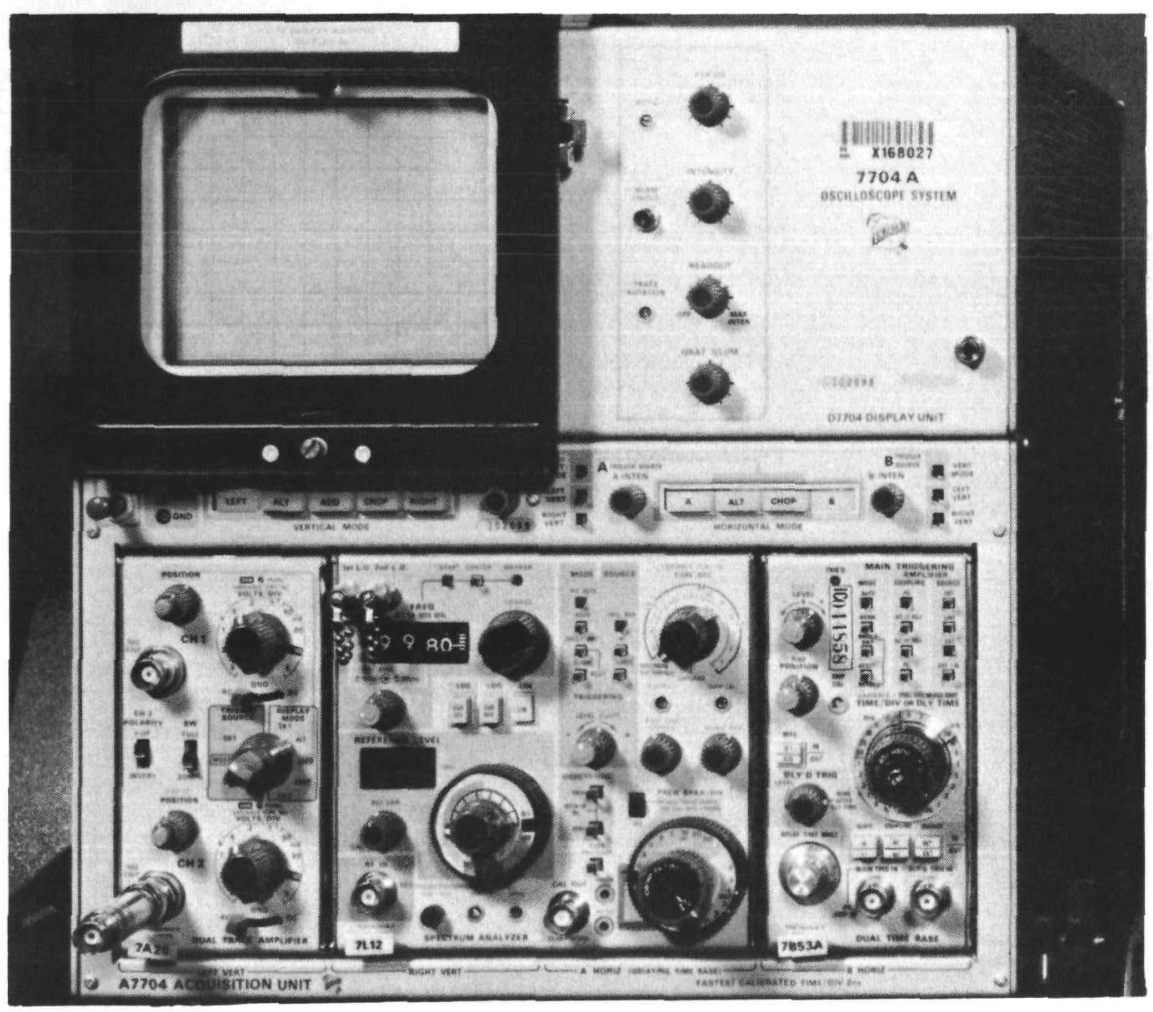

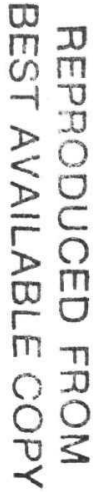

Fig. 8. Spectrum analysis system used to collect rea1-time spectrum response data for ultrasonic systems. 
achieved significant improvement in mechanical stability, as demonstrated by repeated scans of our standards and monitoring of the position of our C-scan recording table with precision dial gage instruments.

Subsequent tests using the new holder demonstrated the need for precise alignment for the higher sensitivity testing in a semiproduction mode. Proper alignment of the blank holder and the search unit assembly was accomplished, and it provides the mechanical stability needed for the improved sensitivity.

\section{CALIBRATION OF THE $0.5-\mathrm{mm}$ TEST}

Since the ultrasonic standard used for the $0.9-\mathrm{mm}$ test was a rolledsurface blank and did not contain a $0.5-\mathrm{mm}$ reference hole, we obtained a ground-surface blank and introduced simulated flaws to establish system standardization procedures and to demonstrate the reproducible detection of the simulated flaws. The Metals Processing Group of the Metals and Ceramics Division at ORNL provided us with a typical 52.1-mm-diam (2.05-in.) ground-surface blank (AC1-6) for use as a calibration standard. We used electrodischarge machining (EDM) to machine three holes halfway through the $0.63-\mathrm{mm}(0.025-\mathrm{in}$.$) thickness to simulate laminar-type flaws.$ The diameters of these simulated flaws were $1.73,0.89$, and $0.48 \mathrm{~mm}$ $(0.068,0.035$, and $0.019 \mathrm{in.})$. In addition to the $0.48-\mathrm{mm}$ primary reference hole, we also drilled holes by using a diamond-tipped drill bit in a procedure established on ceramic materials. Drilled holes of 0.84 , 0.48 , and $0.3 \mathrm{~mm}(0.033,0.019$, and $0.013 \mathrm{in.})$ were introduced. Subsequent scanning of this blank showed that the $0.48-\mathrm{mm}$ holes as well as the $0.3-\mathrm{mm}$ hole could be detected, as indicated in the simulated plan-view C-scan data in Fig. 9. The ring response is produced by scattering from the holder. The three indications in a horizontal line were from the EDM flaws. The largest indication, in the center of the six flaw responses, is from the $1.73-\mathrm{mm}-\mathrm{diam}$ hole. Just above this is the smallest response from the $0.3-\mathrm{mm}$ hole. To the left, the single indication is from the $0.89-\mathrm{mm}$ hole. To the right, the three vertical indications are, from top to bottom, those from the 0.84-, 0.48-, and $0.48-\mathrm{mm}$ holes, respectively. Thus we feel that blank $\mathrm{ACl}-6$ is an adequate standard for the improved sensitivity test. 


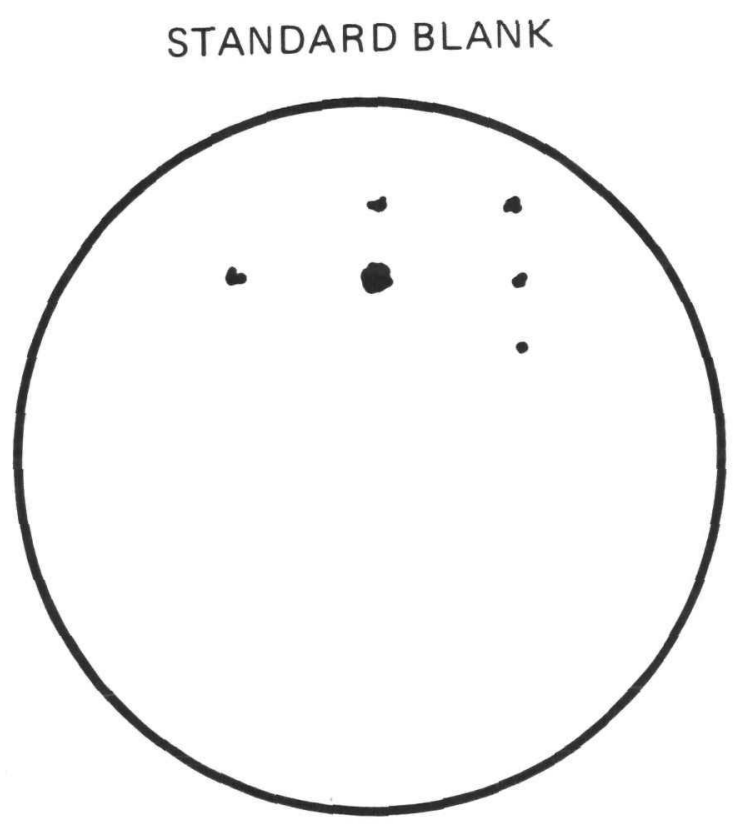

Fig. 9. Simulated plan-view C-scan at $0.5-\mathrm{mm}$ test sensitivity showing the ultrasonic response for six simulated flaws in an iridium DOP-26 blank. The holder for the blank produces the black circular outline.

\section{RESULTS OF THE STUDY}

The results of this effort have provided a system that can be used to inspect blanks for 0.5-mm laminar-type flaws. As an added benefit, the parameter identification system also provides the capability to select replacement and/or backup components. Improvements to the basic mechanical system along with improved alignment provides the necessary mechanical stability to produce plan-view (C-scan) data that can be interpreted for laminar flaws smaller than the $0.5-\mathrm{mm}$ simulated discontinuities. In addition, a primary pulse-echo flaw detection system operating near $20 \mathrm{MHz}$ was determined to be adequate for the $0.5-\mathrm{mm}$ detection requirement. In fact, it appeared that a higher frequency system might be less useful because of the smaller effective beam size. This smaller beam size (more sensitive test) would result in smaller scan indexing than the $0.38 \mathrm{~mm}$ ( $0.015 \mathrm{in}$.) needed for the improved sensitivity 
test. In fact, the $0.38-\mathrm{mm}$ index (along with the slower linear scan that is apparently required by the peak detector circuit in the $s-80$ when operating at about $20 \mathrm{MHz}$ ) almost doubles the time required for inspecting blanks (compared with the $0.9-\mathrm{mm}$ test). Thus, higher frequency inspection without an improved detector response would simply increase the inspection time further. In addition, based on very limited observations, it appears that a higher frequency (about $28 \mathrm{MHz}$ ) would essentially detect only the edges of the laminar flaws and may require dual-frequency testing or dual-test methods to provide the necessary data for flaw evaluation. An example of this phenomenon was noted when one particular nominal 25-MHz search unit was used with the $\mathrm{S}-80$ to interrogate the $1.73-\mathrm{mm}$ hole. At the nominal center frequency (measured by the spectrum analyzer) of about $28 \mathrm{MHz}$, this simulated flaw was resolved so well by the flaw detector system that multiples of the center hole response fell in the time period being gated for a reduced signal flaw response, thereby giving an indication that the area was bonded. Of course, the edges of the hole (or flaw) scattered the high-frequency signal so that indications were produced around the entire boundary of the flaw, which appeared as a ring of flaws encircling a bonded area. However, we would not be comfortable with only the flaw boundary data to interpret.

We have evaluated 56 blanks with the laboratory inspection system. Table 1 documents the results and permits comparison between two fabricating processes for blanks at both ultrasonic sensitivity levels.

The old process used arc-melted and drop-cast $0.5-\mathrm{kg}$ ingots (followed by hot- and cold-rolling operations). In the new process, iridium is alloyed by arc melting and then consumable-arc melted into a cylindrical ingot of approximately $7 \mathrm{~kg}$ for extrusion. The ingot is then extruded to sheet bar and hot and cold rolled into sheet. The new process improves uniformity of microstructure and thus results in decreased rejection due to internal delaminations. As is evident from Table 1 (first column), a11 56 blanks (15 old process, 41 new process) passed the quality assurance program requirement for $0.9-\mathrm{mm}$ sensitivity. The 15 old processed blanks had been previously inspected and, therefore, were known to be acceptable in accordance with the $0.9-\mathrm{mm}$ criteria. Although the rejection rate for ultrasonic inspection of old processed blanks varies, the average has been 
Table 1. Results of ultrasonic inspection at three levels of sensitivity on old and new processed blanks

\begin{tabular}{|c|c|c|}
\hline $\begin{array}{c}\text { Blanks passing } \\
0.9-\mathrm{mm}(0.035-\mathrm{in} .) \\
\text { test }\end{array}$ & $\begin{array}{c}\text { B1anks passing } \\
0.5-\mathrm{mm}(0.020-\mathrm{in} .) \\
\text { test }\end{array}$ & $\begin{array}{l}\text { Blanks with no } \\
\text { indications even at } \\
\text { maximum sensitivity }\end{array}$ \\
\hline \multicolumn{3}{|c|}{ 01d processed blanks } \\
\hline 15 & 15 & 10 \\
\hline \multicolumn{3}{|c|}{ New processed blanks } \\
\hline 41 & 39 & 38 \\
\hline
\end{tabular}

a Problems of reproducibility limit usage.

on the order of $30 \%$. The entire batch of 41 new processed blanks was acceptable by the $0.9-\mathrm{mm}$ criteria. Only two of the total of 56 blanks failed the $0.5-\mathrm{mm}$ test, and these were the new processed blanks (second column). Another observation from Table 1 (third column) indicates that the new process produces fewer small ultrasonic indications than the old process when the blanks are exam-ined with maximum sensitivity; that is, 1 of the 39 new processed blanks and 5 of the 15 old processed blanks had small indication responses.

Figure 10 shows the simulated $\mathrm{C}$-scan flaw detection data at the maximum sensitivity (flaw size unknown but undoubtedly less than the 0.3-mm-diam simulated flaw) for blank A606-3 produced by the old process. Comparison with the $0.5-\mathrm{mm}$ standard reveals an acceptable blank. Our conclusion is that small scatterers of the ultrasound exist near the periphery. We speculate that these small scatterers might possibly affect the weldability at the location of the indication. However, the recorded response in Fig. 10 is only slightly below that of background; that is, the reduction in amplitude is only about $10 \%$ (or about $1 \mathrm{~dB}$ ) to provide the indication. The reliability of such a small change, therefore, would require further development before consideration for routine examination of blanks.

\section{SUMMARY AND CONCLUSIONS}

Oak Ridge National Laboratory has provided flight-quality iridium hardware to the Monsanto Research Corporation, Mound Plant, for several 


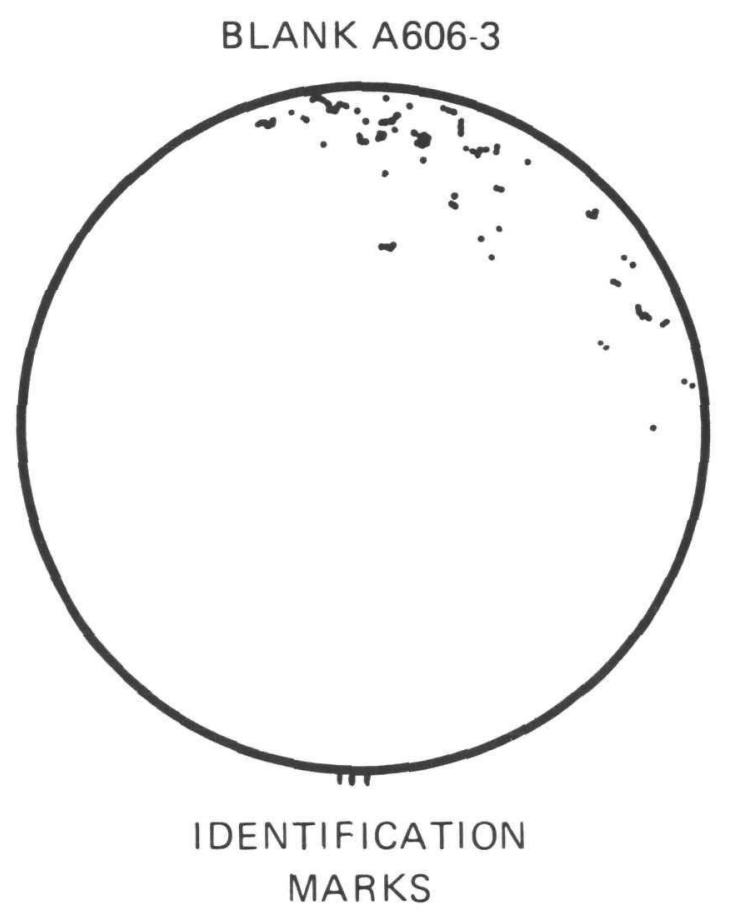

Fig. 10. Simulated plan-view C-scan data at maximum sensitivity showing the ultrasonic response of an iridium blank. The holder for the blank produces the black circular outlines.

years. This material has been routinely inspected for delaminations with an ultrasonic test system. Past capabilities had been limited to the detection and recording of 0.9-mm-diam flaws; however, we have achieved the goal of detecting and recording $0.5-\mathrm{mm}$-diam simulated flaws by (1) selecting improved equipment and search units, (2) designing and assembling an improved laboratory inspection system, (3) establishing modified inspection procedures, and (4) demonstrating the system performance on improved flight-quality hardware blanks.

\section{ACKNOWLEDGMENTS}

The authors are indebted to field engineering personnel D. Kiplinger and $\mathrm{C}$. W. Benton for their input on the improved mechanical scan system. 
We also wish to acknowledge M. M. Martin and R. L. Heestand for review of the manuscript and G. M. Slaughter and M. M. Martin for their guidance and assistance on this effort. We thank J. L. Bishop for her diligent and excellent help with the manuscript, and M. Upton and A. R. McDonald for final preparation. 
page blank 
ORNL- 6290

Distribution

Category UC-25

\section{INTERNAL DISTRIBUTION}

1-2. Central Research Library

3. Document Reference Section

4-5. Laboratory Records Department

6. Laboratory Records, ORNL RC

7. ORNL Patent Section

8. J. A. Carter

9-13. K. V. Cook

14. R. H. Cooper, Jr.

15-19. R. A. Cunningham, Jr .

20. R. L. Heestand

21. K. A. Kitzke

22. E. H. Krieg, Jr.

23. M. M. Martin

24-28. R. W. McClung
29. R. K. Nanstad

30. C. R. Richmond

31. T. K. Roche

32-36. W. A. Simpson, Jr.

37. G. M. Slaughter

38-40. P. T. Thornton

41. F. W. Wiffen

42. R. J. Charles (Consultant)

43. G. Y. Chin (Consultant)

44. H. E. Cook (Consultant)

45. Alan Lawley (Consultant)

46. W. D. Nix (Consultant

47. J. C. Williams (Consultant)

EXTERNAL DISTRIBUTION

48. Battelle Columbus Laboratories, 505 King Avenue, Columbus, OH 43201

C. A. Alexander

49-50. E. I. du Pont de Nemours \& Company, Savannah River Plant, Aiken, SC 29801

J. K. Brown

W. R. Kanne

51-52. Fairchild Industries, 20301 Century Boulevard, Germantown, MD 20767

M. B. Eck

A. Schock

53-58. General Electric Company, Spacecraft Operations, P.0. Box 8555, Room 29B12, Philadelphia, PA 19101
H. M. Dalal
R. J. Hemler
V. F. Haley
P. Gorsuch
J. R. Peterson
R. F. Hartman

59-60. Jet Propulsion Laboratory, California Institute of

Technology, 4800 Oak Grove Drive, Pasadena, CA 91103

R. W. Campbe11

A. E. Wolfe 
61. Johns Hopkins University, Applied Physics Laboratory, Johns Hopkins Road, Laure1, MD 20810

J. C. Hagan

62-65. Los Alamos National Laboratory, P.0. Box 1663, Los Alamos, NM 87545

S. E. Bronisz

T. George

T. C. Wallace, Sr.

R. W. Zocher

66-68. Monsanto Research Corporation, Mound Plant, P.0. Box 32, Miamisburg, $\mathrm{OH} 45342$

W. R. Amos

H. F. Anderson

R. Saylor

69. NUS Corporation, 910 Clopper Road, Gaithersburg, MD 20878

R. W. Englehard

70. Teledyne Energy Systems, 110 W. Timonium Road, Timonium, MD 21093

P. Dick

71. Air Force Weapons Laboratory/AWYS, Kirtland Air Force Base, NM 87117

J. K. Hipp

72-78. Department of Energy, Division of Special Applications, Office of Defense Energy Projects and Special Applications, Office of Nuclear Energy, NE-522, MS B-435, 19901 Germantown Road, Germantown, MD 20874

W. J. Barnett

J. J. Lombardo

G. L. Bennett

A. L. Mowery

R. C. Brouns

K. G. Sommer

J. S. Griffo

79-80. Department of Energy, Albuquerque Operations Office, P.0. Box 5400, Albuquerque, NM 87115

R. Holton

R. Y. Lowrey

81. Department of Energy, Dayton Area Office, P.0. Box 66, Miamisburg, OH 45342

J. A. Morley 
82. Department of Energy, Oak Ridge Operations Office, P.O. Box E, Oak Ridge, TN 37831

Office of Assistant Manager for Energy Research and Development

83. Department of Energy, Savannah River Operations Office, P.0. Box A, Aiken, SC 29801

G. M. Nichols, Jr.

84-260. Department of Energy, Technical Information Center, P.0. Box 62, Oak Ridge, TN 37831

For distribution as shown in DOE/TIC-4500, Distribution Category UC-25 (Materials). 